\title{
55
}

\section{Executive Information Systems in school management: a research perspective}

\author{
Arthur Tatnall \\ Victoria University of Technology \\ Melbourne \\ Australia
}

Bill Davey

RMIT

Melbourne

Australia

\begin{abstract}
Research by the authors has shown that information systems are used in a variety of sophisticated management applications by central and regional educational authorities, but that these systems are used for little more than transaction processing and management reporting at the local school level. The use of Information Technology in Educational Management (ITEM) is becoming increasingly important, particularly with moves towards devolution of school management to the local level. We suggest that the time is right for schools to make more use of IT for decision support at the local level, and advocate the development of school based Executive Information Systems (EIS).
\end{abstract}

Main conference themes: infrastructure

Educational areas:

Study topics:

Secondary keywords: administration, management, research 


\section{INTRODUCTION}

Government schools in Victoria have made significant use of Information Technology in Educational Management (ITEM) for several years. In the last couple of years moves towards school based management have greatly boosted the importance of this area. Our research has shown, however, that in Victoria at least, a major purpose of current information systems in schools is to provide information for use by central education authorities rather than for use by the school itself. We believe that it is time for schools to make more use of IT for decision support at the local level. School Principals share decision making with business executives, who make extensive use of IT for this purpose. Our research suggests that schools could benefit from using IT in this way also.

\section{Management Information Systems in Business}

Traditionally, businesses have often been organized along functional lines and business information systems have thus been designed to support these business functions. Early function specific systems typically stored data items independently, and data collected for use by one system were usually not available to others. However, today information systems can be designed to act together to produce an integrated system providing an information flow across all levels and functions. Data need then only be stored once, without duplication, to support all activities relevant to the organization. The model [1] shown in Figure 1 should be seen not as a single, but as a composite system comprising a number of separate, but cooperating, subsystems, each of which is made up of a suite of custom designed programs.

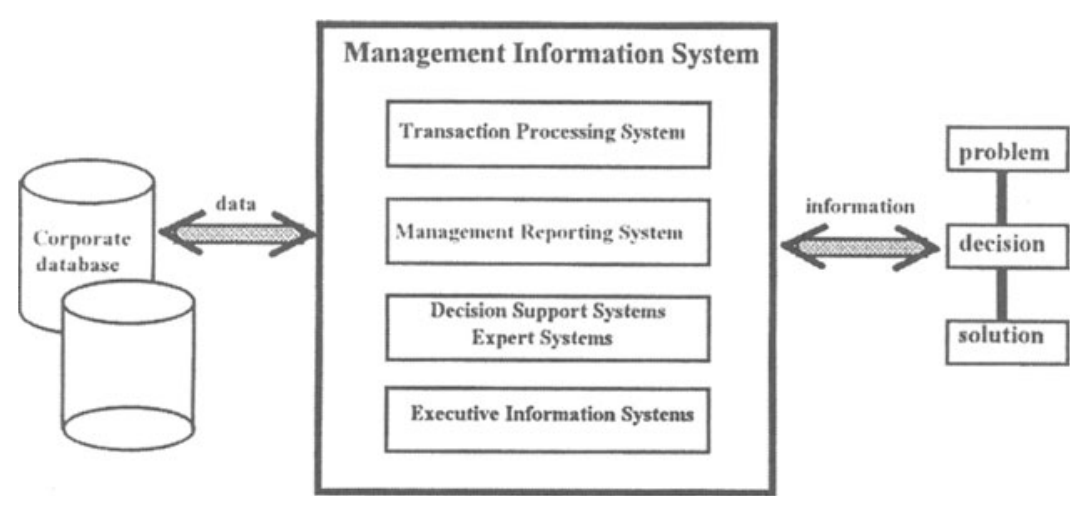

Fig. 1 Integrated information systems 
The function of each of these subsystems is explained below.

1. Transaction Processing Systems (TPS) deal with well structured routine processes, and support many of the day to day operations of the organization.

2. Management Reporting Systems (MRS) are not concerned with such fine detail, but rather with management of activities which support these operations. Summary reports are produced routinely and, although sometimes used for planning and organizing, are used primarily for the controlling of activities.

3. Decision Support Systems (DSS). Unlike the general information support provided by MRSs, Decision Support Systems are designed to assist specific managers in solving specific semistructured problems. Expert Systems are also sometimes used for this purpose.

4. Executive Information Systems (EIS) aim to provide managers with both summary information on the overall performance of the organization, and also the ability to 'drill down' to lower levels to see the actual data. The idea is to provide managers with information about critical success factors, so facilitating their use of management by exception techniques. Decisions made by executives usually have a future orientation and the information used in these decisions is often external and often informal: things such as facts about competitors, Government policy and business trends, and information from trade associations, journals and consultants. The 'strategic business objectives methodology' described by Volonino and Watson [2] takes an organization-wide perspective, first identifying strategic business then identifying and prioritizing critical processes required to support these. The idea of an EIS is to allow executives to review critical success factors on a daily basis to quickly perceive important trends. The system may be set up to automatically flag exceptions and out of control situations by checking against predefined parameters.

\section{THE DEVELOPMENT OF ITEM SYSTEMS IN VICTORIAN SCHOOLS}

In common with many other countries an 'initiation picture' like that described by Visscher [3] applies well to the adoption of ITEM systems in Victorian schools. Like most large organizations the Victorian Education Ministry had for some years made use of a centrally located mainframe. However, use of this facility was for transaction processing functions, such as payroll functions, and did not extend to schools. In line with Visscher's research [3] one of the first administrative software packages used in Victorian schools in the early 1980s 
was BROAD, developed by a science teacher for use on his school's Apple II. Several years later the Education Ministry began to service ITEM by having its administrative computing branch produce an accounting package for school use. The purpose of this package, however, was first and foremost to facilitate the reporting of school data back to the Ministry of Education [4]. Any advantage the software may have provided to schools themselves was secondary to this purpose.

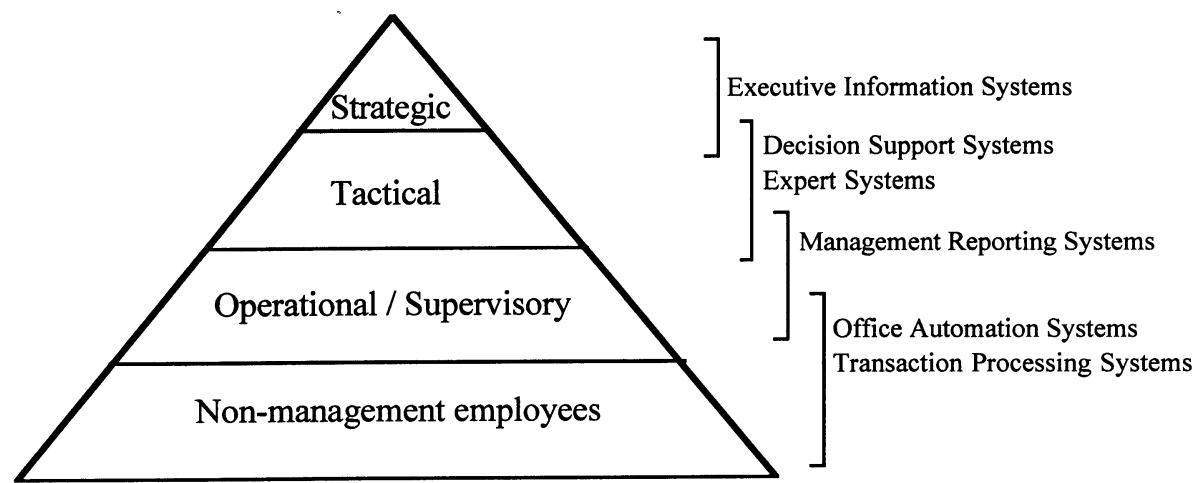

Fig. 2 Levels of use of information systems

Around the world a number of education authorities are making good use of decision support systems in their central or regional offices. Examples such as the Geographic Information and School Facility Planning System in the US State of North Carolina described by Taylor [5], show that the use of ITEM is becoming established in such applications. Few examples in the literature however, indicate much progress in implementing decision support or executive information systems at the local school level. Telem and Barta [6] suggest that at least part of the difficulty here is that the issue of IT assimilation in schools has not, to date, received much attention. For a variety of reasons which we will later discuss, our research suggests that this situation is likely to change soon.

\section{Administrative computing systems currently used in Victorian schools}

There are currently four different computer based management systems in place in Victorian Government schools [4], each of which was custom written by the Directorate of School Education (DSE) and provided free of charge to all schools. 
These systems are:

1. Schools Accounting System (SAS). The Chart of Accounts in this double entry accounting system was designed specifically to allow for the provision of data required centrally by Government accountants.

2. Computer Aided Administrative System (CAAS) is essentially a database system complete with predesigned reports. It is installed in most schools where it is set up to hold student records and staff details.

3. Victorian Certificate of Education Administrative Software System (VASS). The Victorian Certificate of Education (VCE) involves no external examinations, but a number of Common Assessment Tasks. Some of these are externally set and marked, while others are school assessed with external moderation. The large component of school based assessment requires schools to keep much more strict and comprehensive student records than ever before. The VASS system is intended to facilitate this record keeping by providing both a school database of VCE details and results, and a mechanism for the transfer of data between the Board of Studies and schools. Data from the Board is typically sent via modem, while school results are returned on floppy disk.

4. Computerized Administrative Systems Environment in Schools (CASES). SAS, CAAS and VASS are all function specific and the DSE is now introducing a more integrated system which will eventually link: student administration, course selection, timetabling, academic administration, unit goals and student assessment, transport and locations, personnel administration, census reporting, end of year wind down, assets register and system utilities. The DSE describes the CASES development philosophy as placing "great emphasis on an integrated database management system. All school records should be part of an overall construct where a general information system comprising students, staff, assets, facilities and financial data, is readily available to school based personnel to assist in the administrative process."[7]

An examination of how ITEM software is used in our schools [4] shows quite clearly that its main purpose is transaction processing, with a limited amount of management reporting. Furthermore, much of the data which is processed does not even provide information of direct use to the school, but is intended to produce statistics to be sent back to head office. Schools will, of course, be able to use some of the reports generated by these systems to assist with management decision making, but none have been equipped with the models necessary to provide schools with proper educational decision support facilities. A further indication of the level of use of ITEM in schools is the widespread 
use of the term administration, rather than management which is the appropriate term in the school vernacular. Up to this time little effort has gone into building up higher level functionality in these systems such as models for decision support or executive information.

\section{QUALITY EDUCATION, SCHOOL BASED MANAGEMENT AND ITEM}

In Victoria, in common with much of the world, several factors point to a growing need for further improvements in ITEM support. The first of these is a move by many educational organizations to qualify for ISO9001 accreditation. Hopefully this trend is a reflection of attempts by educational authorities to use quality assurance practices to produce improved educational institutions. In Victoria the Technical and Further Education (TAFE) colleges have made significant steps towards accreditation, the university system is being monitored with regards to quality, and the school system is being put through a programme called 'Schools of the Future', part of which relates to quality assurance. The common thread which runs through, is the need to close the loop from strategic aims in the mission statement to tactical objectives, measurement of performance criteria and hence improvement.

\section{School based management}

In 1994 the Victorian Government piloted a programme in which a number of selected schools became, to a large degree, self managing 'Schools of the Future'. This move towards the 'Self Managing School' is echoed elsewhere as 'Schools Renewal' (NSW), 'Better Schools' (Western Australia), 'Tomorrow's Schools' (New Zealand), 'Site based Management' (USA) and 'Local Management of Schools' (UK) [8]. The intention is to devolve much of the administration, formerly done centrally, to these self managing schools. This means that assets management and finances, additional personnel tasks such as teacher absences and leave, and some payroll functions will devolve to the school level, as well as student administration. The schools will be required to do much of their reporting to the DSE from CASES via modem, and use of this software will become essential. An article in the DSE's Education News explains that "CASES is central to enabling 'Schools of the Future' to perform functions associated with self management and also for the operation of efficient school based administrative systems." [9] It adds that CASES will be used "to link schools to an electronic wide area network (WAN) whereby schools will be able to link to the corporate system to maintain and retrieve basic personnel data, payroll entitlements and disbursement data." [9] This link was still to be implemented in January 1995. 


\section{Business practice related to ITEM support in schools}

An important difference between the business manufacturing model and its educational analogue is the need for a wider range of information in the educational version due to the complexity of the educational 'product'. Management functions in schools can, like other organizations, be considered in terms of the need to make operational, tactical and strategic decisions. School budgets, for instance, are concerned with the allocation of personnel resources amongst possible duties in line with the school's mission statement. The mission and strategic plan are, in theory, set by the School Council, while tactical and operational plans are devised by professional school management.

To illustrate some software tools which can be introduced at each management level, take a simplistic look of some of the tasks undertaken in the functional areas of school budget and human resources management. Overall aim is to determine strategic aims, tactical objectives and then operational plans. We are familiar with the way in which a computer keeps track of receipts and expenditures, or prepares a staffing return or student census. However, the possibilities are far broader if we think of the whole management process. Management functions could be supported as follows:

Table 1 Supporting information system components

\begin{tabular}{lll}
\hline Level & Budget & Human Resources Management \\
\hline Operational & $\begin{array}{l}\text { Record and retrieve expense and } \\
\text { income transactions }\end{array}$ & $\begin{array}{l}\text { Record and retrieve staff details and } \\
\text { movements }\end{array}$ \\
Tactical & $\begin{array}{l}\text { Comparison reports between } \\
\text { budget and expenditures }\end{array}$ & $\begin{array}{l}\text { Preparation of staffing returns including } \\
\text { difference from staffing establishment }\end{array}$ \\
Strategic & $\begin{array}{l}\text { Trend analysis, sensitivity } \\
\text { analysis, inclusion of external data } \\
\text { in models }\end{array}$ & Future needs analysis, skills audit \\
\hline
\end{tabular}

Consider a hypothetical example in which the School Council has decided to make technology education a high priority for the school. This could lead to a number of strategic objectives: increasing availability of equipment, increasing technology skills of staff, developing new curricula and so on. Tactical planning might then take one of many paths such as: increasing the amount of money available for technology purchase through fund raising or grant submissions, changing budget allocations to favour technology purchase, hiring new staff with greater technology skills or retraining current staff. These strategies would then be implemented with a number of operational plans. 
The sequence should be:

mission statement $\rightarrow$ strategic plan $\rightarrow$ tactical plan $\rightarrow$ operational plan.

Each stage of the realisation of the mission can benefit from the use of ITEM and there is a need for far more that just the current software support for operations.

\section{Research into changing school management perceptions}

The authors have investigated the realities of management style and ITEM support in Victorian schools. Triangulation was attempted through interviewing principals, conducting textual analyses of school management documents, discussions with central education authorities, and observation of management processes.

The school population in Victoria is segmented into government and nongovernment sectors, and management issues differ in each. Nongovernment (private and catholic) schools have a long history of being managed from the local school level with only minimal centralized control, and the teaching payroll has always been handled locally. The situation in Government schools, on the other hand, has been one of central administrative control. But things are changing in the management of these schools which have only recently seen genuine school based management initiatives, and our research shows that:

- Principals are becoming more aware of their role as school based managers.

- School communities have extra responsibilities inherent in school based management and will need IT support in their decision making to an extent not yet possible.

- There is little awareness or availability of suitable ITEM software above the management reporting level, and software support has progressed through the classical model of development seen in most other areas.

- The level of training of Principals in ITEM systems (and particularly in DSS and EIS) has not reached maturity.

Nongovernment schools have been managed as largely independent units but apart from a difference in ITEM software we found little difference in quality or level of use to that found in government schools.

\section{CONCLUSION: A CASE FOR THE USE OF EIS IN SCHOOLS}

Our research has shown that in Victoria, and probably much of the world, information systems are used at the local school level for little more than 
transaction processing and management reporting. But are schools sufficiently similar to businesses to profitably adopt EISs? Our answer to this question is yes. A typical secondary school in this state has a budget of Australian $\$ 4 \mathrm{M}$ $\$ 6 \mathrm{M}$, and employs 60 - 100 staff, making it the size of a medium sized business. Principals we spoke to easily identified the school mission and strategic plan, and a number of critical success factors for measuring its fulfilment. These included size of enrolment, number of inquiries, retention rates, tertiary entry rates, employment rates, number of fights in the school yard, number of pupils suspended this month, parent and community perceptions of school, and so on.

As information systems academics, we can see how it would be readily possible for a school to build an EIS to provide its 'managers' with just that information useful to them in particular. Most of the raw data needed is currently stored in present ITEM systems and, as a first step, little more would be needed than to build a custom designed Visual Basic 'front end' to this data. We expect to see a number of such developments in the near future.

\section{REFERENCES}

1. Tatnall, A., Davey, W. and Burgess, S. (1995) Management Information Systems: an introduction. 2nd edition, Data Publishing, Melbourne.

2. Volonino, L. and Watson, H. J. (1991) The Strategic Business Objectives Method for guiding Executive Information Systems development, Journal of Management Information Systems, 7 (3).

3. Visscher, A. J. (1994) Computer assisted school administration and management: where are we and where should we go?, Information Technology in Educational Management, (eds. Barta, B., Telem M., and Gev, Y), Chapman \& Hall, London.

4. Tatnall, A. (1994) Information Technology and the Management of Victorian Schools - providing flexibility or enabling better central control?, Information Technology in Educational Management, (eds. Barta, B., Telem M., and Gev, Y.), Chapman \& Hall, London.

5. Taylor, R. G. (1994) Geographic Information and School Facility Planning, Information Technology in Educational Management, (eds. Barta, B., Telem M., and Gev, Y.), Chapman \& Hall, London. 
6. Telem, M., and Barta, .B. (1994) Information Technology assimilation in school: a theoretical and practical framework, Information Technology in Educational Management, (eds. Barta, B., Telem M., and Gev, Y.), Chapman \& Hall, London.

7. Directorate of School Education, Victoria (1993) Computerised Administrative Systems Environment in Schools - MS-DOS desktop computer hardware specifications.

8. Collier, Janine and Tregenza, Karen (1994); Selling your school?, in Changing Education: a journal for teachers and administrators, 1 (1), Deakin University, Victoria.

9. Directorate of School Education, Victoria (1994) CASES - information technology for Schools of the Future, in Education News, February 1994. 